\title{
Thiamine status, metabolism and application in dairy cows: a review
}

\author{
Xiaohua Pan ${ }^{1,2 *}$, Xuemei Nan ${ }^{1}$, Liang Yang ${ }^{1}$, Linshu Jiang ${ }^{3}$ and Benhai Xiong ${ }^{1 *}$ \\ ${ }^{1}$ State Key Laboratory of Animal Nutrition, Institute of Animal Science, Chinese Academy of Agricultural Sciences, Beijing \\ 100193, People's Republic of China \\ ${ }^{2}$ State Key Laboratory of Food Science and Technology, School of Food Science and Technology, Jiangnan University, Wuxi \\ 214122, People's Republic of China \\ ${ }^{3}$ Beijing Key Laboratory for Dairy Cow Nutrition, Beijing University of Agriculture, Beijing 102206, People's Republic of China
}

(Submitted 29 November 2017 - Final revision received 24 April 2018 - Accepted 24 May 2018 - First published online 10 July 2018 )

\begin{abstract}
As the co-enzyme of pyruvate dehydrogenase and $\alpha$-ketoglutarate dehydrogenase, thiamine plays a critical role in carbohydrate metabolism in dairy cows. Apart from feedstuff, microbial thiamine synthesis in the rumen is the main source for dairy cows. However, the amount of ruminal thiamine synthesis, which is influenced by dietary $\mathrm{N}$ levels and forage to concentrate ratio, varies greatly. Notably, when dairy cows are overfed high-grain diets, subacute ruminal acidosis (SARA) occurs and results in thiamine deficiency. Thiamine deficiency is characterised by decreased ruminal and blood thiamine concentrations and an increased blood thiamine pyrophosphate effect to $>45 \%$. Thiamine deficiency caused by SARA is mainly related to the increased thiamine requirement during high grain feeding, decreased bacterial thiamine synthesis in the rumen, increased thiamine degradation by thiaminase, and decreased thiamine absorption by transporters. Interestingly, thiamine deficiency can be reversed by exogenous thiamine supplementation in the diet. Besides, thiamine supplementation has beneficial effects in dairy cows, such as increased milk and component production and attenuated SARA by improving rumen fermentation, balancing bacterial community and alleviating inflammatory response in the ruminal epithelium. However, there is no conclusive dietary thiamine recommendation for dairy cows, and the impacts of thiamine supplementation on protozoa, solid-attached bacteria, rumen wall-adherent bacteria and nutrient metabolism in dairy cows are still unclear. This knowledge is critical to understand thiamine status and function in dairy cows. Overall, the present review described the current state of knowledge on thiamine nutrition in dairy cows and the major problems that must be addressed in future research.
\end{abstract}

Key words: Thiamine: Dairy cows: Rumen: Subacute ruminal acidosis

Thiamine $\left(\mathrm{C}_{12} \mathrm{H}_{16} \mathrm{~N}_{4} \mathrm{OS}\right)$, also known as vitamin $\mathrm{B}_{1}$, is a watersoluble substance. Thiamine has considerable metabolic importance due to its role as a cofactor in carbohydrate and energy metabolism in organisms ${ }^{(1)}$. Almost $90 \%$ of ruminal thiamine is synthesised by microorganisms, with the rest coming from feedstuff $^{(2)}$. In National Research Council recommendations ${ }^{(3)}$, the ruminal synthesis of thiamine was estimated to be $143 \mathrm{mg} / \mathrm{d}$ for a $650-\mathrm{kg}$ cow producing $35 \mathrm{~kg}$ of $4 \%$ fat-corrected milk/d; this amount seems to meet the requirement of dairy cows, which was assumed to be approximately $21-47 \mathrm{mg} / \mathrm{d}^{(4)}$. Therefore, there is no dietary thiamine recommendation in the National Research Council ${ }^{(3)}$. However, the estimated thiamine synthesis of lactating cows in the National Research Council ${ }^{(3)}$ were extrapolated from steer data of Miller et al. ${ }^{(5)}$ and Zinn et al. ${ }^{(6)}$. To investigate the validity of the extrapolated approach in the National Research Council ${ }^{(3)}$, Schwab et al. ${ }^{(7)}$ measured ruminal apparent synthesis (AS) of thiamine in dairy cows $(51 \mathrm{mg} / \mathrm{d})$, and calculated National Research Council ${ }^{(3)}$ estimation of thiamine AS $(127 \mathrm{mg} / \mathrm{d})$ by adjusting to the measured DM intake of dairy cows, and they found that thiamine synthesis was overestimated in the National Research Council ${ }^{(3)}$. Furthermore, thiamine deficiencies have been found in steers when diets are high in sulphate ${ }^{(8)}$ or when diets cause a sudden drop in ruminal $\mathrm{pH}^{(6)}$. Indeed, numerous studies have shown positive responses in dairy cows to thiamine supplementation, such as increased milk and milk component production ${ }^{(9,10)}$ and attenuated subacute ruminal acidosis (SARA) ${ }^{(11-13)}$. To update our knowledge of thiamine in dairy cows and to ascertain the effects of thiamine on dairy cow performance and metabolism, the current literature is reviewed herein covering thiamine synthesis in the rumen, the amount of thiamine arriving at the duodenum, the effects of thiamine supplementation on milk performance and the mode of action of thiamine on rumen fermentation, especially regarding SARA attenuation.

\footnotetext{
Abbreviations: AS, apparent synthesis; LPS, lipopolysaccharide; SARA, subacute ruminal acidosis; TPP, thiamine pyrophosphate

* Corresponding authors: Dr X. Pan, email panxiaohuacaas@163.com; Professor B. Xiong, email xiongbenhai@caas.cn
} 


\section{Biochemical functions and application of thiamine in ruminants}

Thiamine is an essential nutrient for dairy cows and other mammals. By serving as a cofactor of enzymes, including transketolase, $\alpha$-ketoglutarate dehydrogenase, pyruvate dehydrogenase, and branched chain $\alpha$-keto acid dehydrogenase, thiamine plays a critical role in carbohydrate metabolism ${ }^{(12)}$. Independent of its role as a co-enzyme, thiamine also has specific roles in neuronal communication, immune system activation, signalling and maintenance processes in cells and tissues ${ }^{(12)}$. Severe thiamine deficiency in cattle leads to various clinical effects, from anorexia to polioencephalomalacia ${ }^{(13)}$, while the clinical polioencephalomalacia is not the main point of this review and will not be discussed in detail. For rumen bacteria, thiamine is indispensable for the growth of the rumen bacteria Ruminococcus albus ${ }^{(14)}$ and Ruminococcus flavefasciens ${ }^{(15)}$, serves as a cofactor of phosphoenolpyruvate decarboxylase in Bacteroides fragilis ${ }^{(16)}$ and participates in the production of acetyl-CoA via pyruvate-ferredoxin oxidoreductase in Megasphaera, Selenomonas ruminantium, Butyrivibrio fibrisolvens and Ruminococcus ${ }^{(17)}$.

Due to the key functions of thiamine in dairy cows and rumen bacteria, a thorough understanding of thiamine status in dairy cows is crucial, and there has been more focus on supplying thiamine in ruminant diets. For example, Shaver \& $\mathrm{Bal}^{(9)}$ found that the milk and component production tended to be increased by thiamine supplementation $(300 \mathrm{mg} / \mathrm{d})$ when dairy cows fed diets high in non-fibre carbohydrate. Similarly, Kholif et $a l^{(10)}$ also found that feeding lactating cows a daily ration supplemented with $340 \mathrm{mg}$ of thiamine increased milk yield, milk fat and protein yields. The improvement in milk performance may be related to an increase in precursors of milk components due to thiamine supplementation, since Solouma et $a l .{ }^{(18)}$ demonstrated that adding $40 \mathrm{mg} / \mathrm{d}$ thiamine to the diet of sheep significantly increased the blood concentrations of albumin, globulin and glucose. However, there are discrepancies surrounding the effects of thiamine on ruminant's metabolism. Rowghani et al. ${ }^{(19)}$ found that thiamine supplementation (0, 4 and $6 \mathrm{mg} / \mathrm{kg} \mathrm{DM})$ in lambs fed a high concentrate diet had no effect on blood glucose level. Silzell et $a l .{ }^{(20)}$ reported that supplemental thiamine did not improve zantibody response and cell-mediated immune response. The inconsistent results concerning the effect of thiamine on ruminant metabolism may be related to differences in thiamine supplementation levels, dietary nutritional composition and physiological stage.

\section{Microbial synthesis, degradation and absorption of thiamine in the gastrointestinal tract of ruminants}

The requirement for thiamine in ruminants is mainly met by microbial synthesis, with a small portion coming from feedstuffs degradation. The thiamine content is higher in cereal feeds than in forage feedstuffs (Table 1). Similarly, Tafaj et al. ${ }^{(25)}$ reported a higher thiamine content in concentrate than in hay $(3.78 \mathrm{v}$. $0.4 \mathrm{mg} / \mathrm{kg} \mathrm{DM})$, and different concentrate:hay ratios influenced dietary thiamine intake. However, ruminal thiamine concentration was negatively correlated with dietary thiamine intake and was assumed to be more closely related to the concentrate level than to dietary thiamine content because of the effect of concentrate on rumen conditions ${ }^{(25)}$. The actual ruminal thiamine synthesis by microbes is extremely difficult to measure as the rumen is a dynamic system in which thiamine synthesis, degradation and absorption occur simultaneously during passage along the digestive tract ${ }^{(5,7,23,26,27)}$. Therefore, ruminal thiamine AS is calculated by subtracting daily ortscorrected thiamine intake from the amount reaching the duodenum. This calculation does not reflect actual thiamine synthesis, as it ignores ruminal degradation, microbial use, or potential absorption across the rumen wall. The thiamine AS has been measured in some studies and data are provided in Table 2. Schwab et al. ${ }^{(7)}$ reported that the average ruminal thiamine AS in lactating dairy cows is $50.6 \mathrm{mg} / \mathrm{d}$, which is similar to the value of $51.7 \mathrm{mg} / \mathrm{d}$ reported by Breves et al. ${ }^{(2)}$ and $>26.0 \mathrm{mg} / \mathrm{d}$ reported by Santschi et al. ${ }^{(29)}$. In the recent studies by Beaudet et al. ${ }^{(23)}$, Castagnino et al. ${ }^{(27)}$ and Seck et al. ${ }^{(28)}$, the ruminal thiamine AS was negative (from -39.8 to $0.8 \mathrm{mg} / \mathrm{d}$ ), which they hypothesised was due to thiamine destruction by thiaminase enzymes or degradation by the ruminal microflora. Based on the above studies, we can conclude that dietary

Table 1. Summary of thiamine concentrations of several feeds

\begin{tabular}{|c|c|c|}
\hline Feedstuff & $\begin{array}{l}\text { Range of thiamine } \\
(\mathrm{mg} / \mathrm{kg} \mathrm{DM})\end{array}$ & References \\
\hline Alfalfa meal & 3.4-3.9 & National Research Council(21) \\
\hline Alfalfa hay & $0.36-2.92$ & Castagnino et al. ${ }^{(22)}$, Schwab et al. ${ }^{(7)}$, Beaudet et al. ${ }^{(23)}$ \\
\hline Grass hay & $0.89-1.49$ & Schwab et al. ${ }^{(7)}$, Beaudet et al. ${ }^{(23)}$ \\
\hline Maize silage & $0.57-1.37$ & Schwab et al. ${ }^{(7)}$, Beaudet et al. ${ }^{(23)}$ \\
\hline Maize, ground & $2 \cdot 1-3 \cdot 84$ & Schwab et al..$^{(7)}$, National Research Council ${ }^{(21)}$, Castagnino et al. ${ }^{(22)}$ \\
\hline Barley, ground & $3.9-4.5$ & Schwab et al. ${ }^{(7)}$, National Research Council ${ }^{(21)}$ \\
\hline Oat grain & $5 \cdot 2-6.5$ & National Research Council ${ }^{(21)}, \mathrm{McDowell}^{(24)}$ \\
\hline Sorghum grain & 3.0-3.9 & National Research Council (21), McDowell(24) \\
\hline Wheat grain & $4.5-5.5$ & National Research Council ${ }^{(21)}, \mathrm{McDowell}^{(24)}$ \\
\hline Wheat bran & 8.0 & National Research Council ${ }^{(21)}$, McDowell $^{(24)}$ \\
\hline Soyabean hulls & $1 \cdot 73-1 \cdot 8$ & Schwab et al. ${ }^{(7)}$, Beaudet et al. ${ }^{(23)}$ \\
\hline Beet pulp & $0.4-0.95$ & Schwab et al. ${ }^{(7)}$, Beaudet et al. ${ }^{(23)}$, National Research Council ${ }^{(21)}$ \\
\hline Soyabean meal & $1.96-4.5$ & Beaudet et al. ${ }^{(23)}$, National Research Council ${ }^{(21)}$, Castagnino et al. ${ }^{(22)}$ \\
\hline Cottonseed meal & $6 \cdot 4-7 \cdot 0$ & National Research Council ${ }^{(21)}, \mathrm{McDowell}^{(24)}$ \\
\hline Distiller's dried solubles & $2 \cdot 9-6.9$ & National Research Council(21), McDowell ${ }^{(24)}$ \\
\hline
\end{tabular}




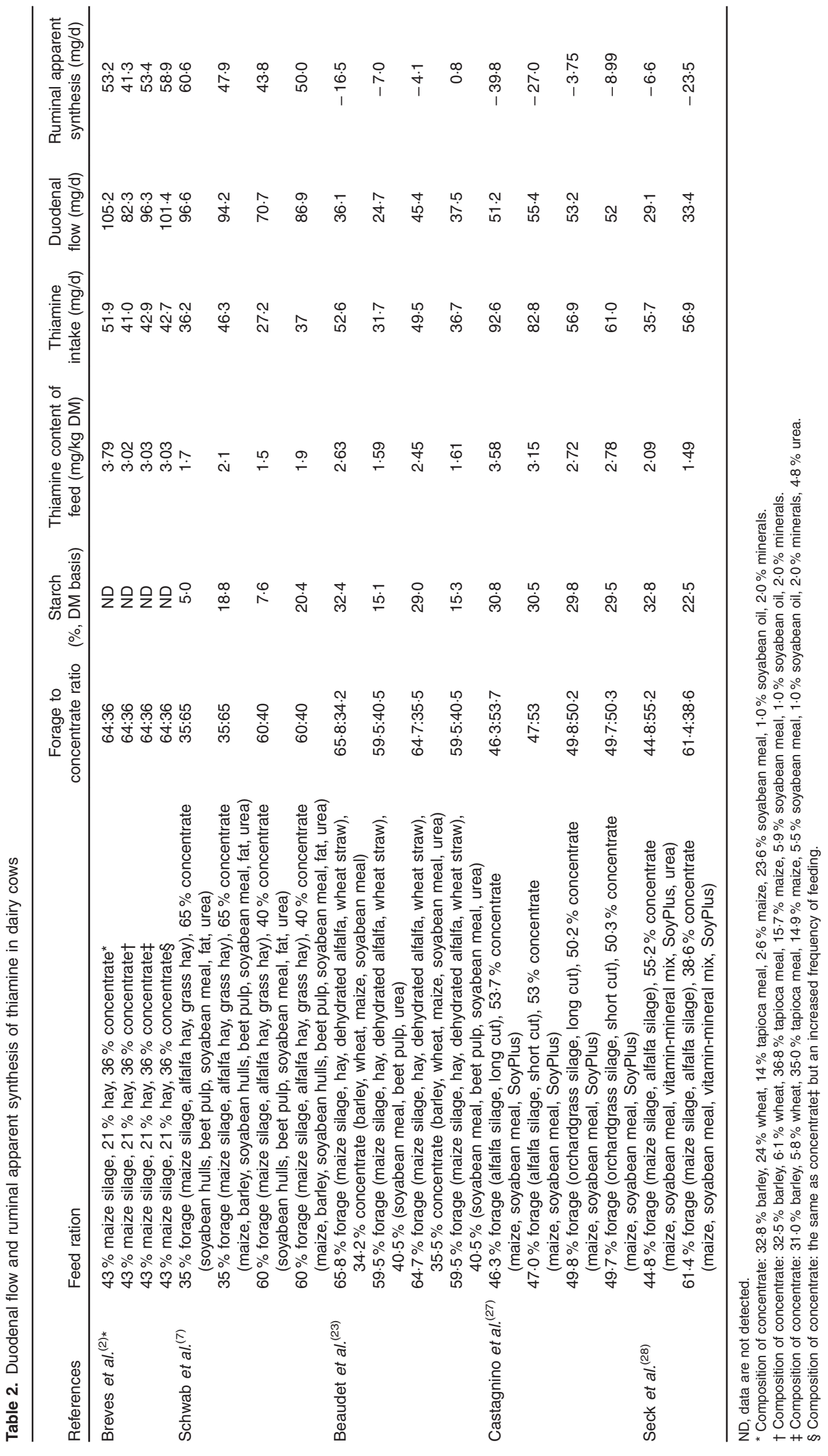


factors such as feed type and nutrient composition influences thiamine synthesis. Castagnino et al. ${ }^{(27)}$ reported that long cut alfafa silage reduced thiamine AS which proved that feed type affects thiamine synthesis in the rumen. In addition, Buziassy \& Tribe $^{(30)}$ found that the thiamine concentration in rumen fluid was significantly reduced when dietary protein levels decreased. Breves et al. ${ }^{(2)}$ showed that ruminal actual thiamine synthesis and the amount of thiamine flowing to the duodenum decreased when $26 \%$ of dietary $\mathrm{N}$ was deducted from the diet, and the amount of ruminal thiamine synthesis positively correlated with duodenal microbial $\mathrm{N}$ flow $(R 0.76)$, indicating that dietary $\mathrm{N}$ levels and microbial metabolism in the rumen affect thiamine synthesis.

In addition to dietary $\mathrm{N}$, dietary carbohydrate sources and levels also affect ruminal thiamine synthesis. Schwab et al. ${ }^{(7)}$ discovered that increasing non-fibre carbohydrates from 30 to $40 \%$ tended to decrease daily ruminal thiamine AS in cows fed a $35 \%$ forage diet, and the opposite effect occurred for cows fed a $60 \%$ forage diet. Castagnino et al. ${ }^{(27)}$ reported that thiamine AS was negatively correlated with the amounts of organic matter and ruminally digested starch. Tafaj et $a l .{ }^{(25)}$ also found that ruminal thiamine content was higher under conditions of 40 and $25 \%$ concentrate in the diet than under conditions of 50 and $60 \%$ concentrate, despite higher thiamine content in concentrate than in forage feedstuff. Thus, Tafaj et al. ${ }^{(25)}$ assumed that the ruminal thiamine concentration was more closely related to the concentrate level, that is the intake of energy and digestible organic matter, than to the dietary thiamine content. The effect of dietary carbohydrates on thiamine concentration may be due to its influence on rumen fermentation and the microbial community. Castagnino et al. ${ }^{(27)}$ and Seck et al. ${ }^{(28)}$ reported a positive correlation between ruminal $\mathrm{pH}$ and thiamine AS. The impact of $\mathrm{pH}$ on thiamine status may be related to the increasing thiaminase production at low ruminal $\mathrm{pH}$, since $\mathrm{pH}$ values below $5 \cdot 8^{(31)}$ are optimal for thiaminase-producing bacteria (C. sporogenes and a few species of Bacillus; Brent \& Bartley $^{(32)}$ ), as a result, thiamine degradation by microbial thiaminase increased. Besides, thiamine synthesis by Bacteroidetes, Fibrobacter and Pyramidobacter decreased under low ruminal $\mathrm{pH}$ condition ${ }^{(33)}$, which also contribute to their positive correlation between ruminal $\mathrm{pH}$ and thiamine AS. However, Schwab et al. ${ }^{(7)}$ reported a negative correlation between thiamine AS and ruminal $\mathrm{pH}$ values, whereas Beaudet et al. ${ }^{(23)}$ didn't find any relationship between these two parameters. This discrepancy may be related to the different extent of $\mathrm{pH}$ decrease under different dietary conditions: in the study of Castagnino et $a l^{(27)}$, the average ruminal $\mathrm{pH}$ values for dairy cows fed alfalfa silage and grass silage are 6.26 and 5.84, respectively; Seck et al. ${ }^{(28)}$ reported that $\mathrm{pH}$ values of dairy cows fed high forage and low forage are 6.0 and $5 \cdot 86$, respectively; whereas the ruminal $\mathrm{pH}$ values in the study by Schwab et $a l .{ }^{(7)}$ were approximately above $6 \cdot 0$, thus there was less thiaminase available to degrade thiamine.

Ruminal thiamine exists in a free or bound form or contained in rumen microorganisms. Currently, the proportion of thiamine absorbed in the rumen and intestine is difficult to determine and is unclear. The disappearance rate was used to indicate thiamine fate in the gastrointestinal tract in the study by Santschi et al. ${ }^{(29)}$, who found that $67.8 \%$ of thiamine disappears before the duodenum and that there is almost no disappearance of postruminally infused thiamine before the duodenum, suggesting extensive ruminal destruction or utilisation of thiamine. Zinn et $a l^{(6)}$ reported the ruminal disappearance rate of thiamine is $47.7 \%$. The fate of thiamine that disappears from the rumen is unclear, and it is unknown whether thiamine absorption can occur in the rumen. Through permeability measurements on sheep rumen mucosa at several thiamine concentrations $(0 \cdot 1-12 \cdot 8 \mu \mathrm{g} / \mathrm{ml})$, Hoeller et al. ${ }^{(34)}$ found that the rumen wall mucosa has a low permeability to thiamine. Similarly, Smith \& Marston ${ }^{(35)}$ demonstrated that thiamine is not absorbed in appreciable amounts through the rumen wall. However, Rérat et $a l .{ }^{(36)}$ and McDowell ${ }^{(37)}$ reported that the rumen wall is just not permeable to bound thiamine or thiamine contained in rumen microorganisms, but ruminants can absorb free thiamine from the rumen wall by an active transport mechanism. Regarding intestinal thiamine absorption, the intestinal disappearance of thiamine is $75 \%{ }^{(29)}$, and $90-96 \%$ of thiamine that reaches the duodenum in sheep is in a microbial fraction $^{(38)}$, indicating the high absorption of microbially produced thiamine in the intestine. Free thiamine can be degraded by ruminal microbes or absorbed through the rumen wall, while the absorption of bound thiamine or thiamine in ruminal microorganisms mainly occurs in the intestine and plays an important role in supplying this nutrient to host ruminants.

\section{Subacute ruminal acidosis induction altered thiamine status in ruminants}

As mentioned above, increasing dietary non-fibre carbohydrate levels can decrease the daily AS of thiamine in the rumen ${ }^{(7)}$ and may cause thiamine deficiency. SARA caused by overfeeding a high-grain diet is known to reduce ruminal $\mathrm{pH}$ and microbial activity $^{(39)}$ and may, therefore, affect thiamine production. The relationship between thiamine status and SARA has attracted increasing attention. Recently, researchers ${ }^{(11,40,41)}$ have reported that thiamine deficiency occurs when sheep or cattle have subacute or acute ruminal acidosis. To better understand how SARA induction interacts with thiamine status, the methods for diagnosing thiamine deficiency and the impact and possible mechanisms of SARA on ruminal and blood thiamine concentrations are reviewed in the following section and summarised in Fig. 1.

\section{Thiamine deficiency diagnosis}

The erythrocyte thiamine pyrophosphate (TPP) effect is a criteria for assessing thiamine status, and thiamine deficiency can be diagnosed when TPP effect is $>45 \%{ }^{(42)}$. Recent literatures demonstrated that blood TPP effect increased along with rumen acidosis induction, for example, Dabak \& Gul ${ }^{(40)}$ found that the mean TPP effect was $25.5 \%$ in normal sheep and $59.4 \%$ in sheep with chronic ruminal acidosis; Karapinar et al. ${ }^{(41)}$ also demonstrated that the TPP effect was significantly higher in feedlot cattle fed a high concentrate diet (47.2\%) than in control cattle (19.5\%).

Other criteria of thiamine deficiency include increased lactate and pyruvate concentrations in the blood due to the impaired 


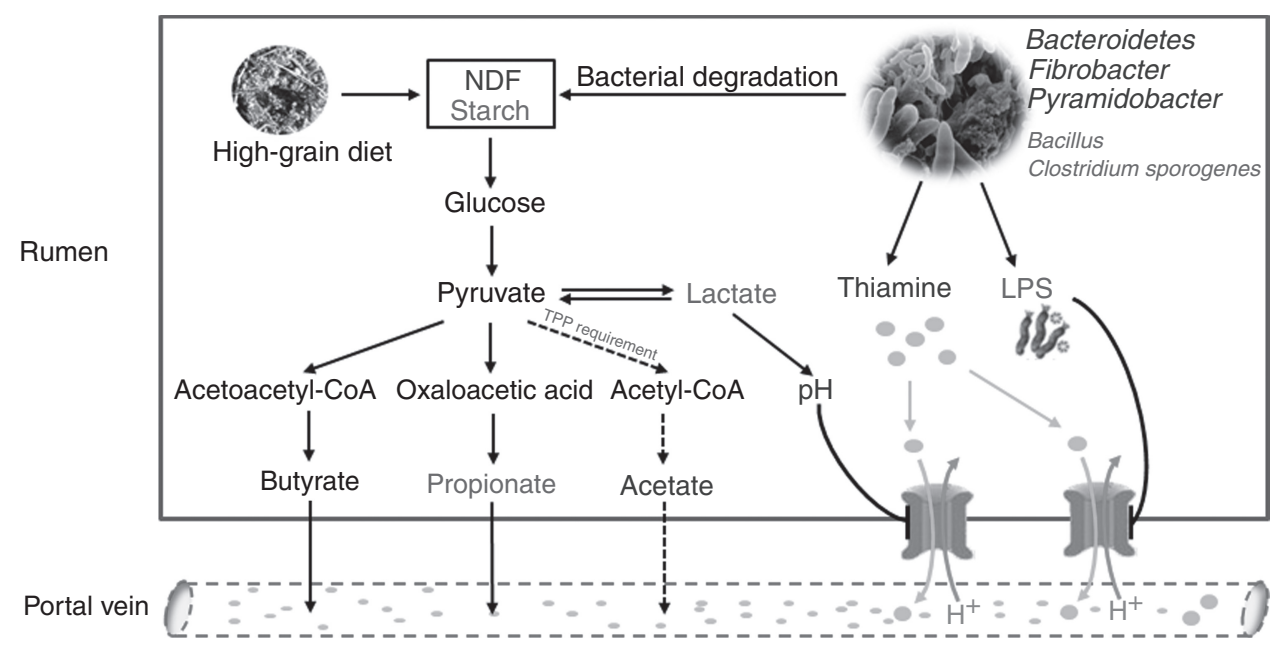

Fig. 1. The potential mechanisms by which high-grain-induced subacute ruminal acidosis alters thiamine status in the rumen and blood of dairy cows. When dairy cows are fed a high-grain diet, more starch and less neutral-detergent fibre (NDF) reach the rumen. Then, carbohydrates are decomposed to volatile fatty acids (VFA) through pyruvate by bacterial degradation. During this process, pyruvate accumulates, and more thiamine (in the form of the cofactor thiamine pyrophosphate (TPP)) is needed for the conversion of pyruvate to acetyl-CoA. As a result, thiamine concentrations decrease, and more pyruvate flows to lactate and propionate, resulting in decreased pH. In addition, the abundance of thiamine-synthesising bacteria, including Bacteroidetes, Fibrobacter and Pyramidobacter, decrease, whereas those of thiamine-degrading bacteria, such as Bacillus and $C$. sporogenes, increase under high-grain feeding; these changes also contribute to decreased thiamine concentrations in the rumen. Decreased ruminal thiamine content and hampered thiamine transport in response to low ruminal pH and lipopolysaccharide (LPS) accumulation act together to alter thiamine status in the blood. Red text, increase; blue text, decrease.

co-enzyme function of thiamine in enzymatic decarboxylation reactions ${ }^{(43)}$. Dabak \& Gul ${ }^{(40)}$ found that increased L-lactate and pyruvate concentrations in sheep with chronic ruminal acidosis were probably related to thiamine deficiency. In addition, blood thiamine concentrations are suggested as an indicator of thiamine status. Hill et al. ${ }^{(44)}$ proposed a reference range of $19 \cdot 90$ $49.09 \mu \mathrm{g} / \mathrm{l}$ for cattle, and concentrations below $13 \cdot 27 \mu \mathrm{g} / \mathrm{l}$ are considered indicative of deficiency. Gooneratne et al. ${ }^{(45)}$ found that the average blood thiamine concentration was 49.2 (SD 14.9) $\mu \mathrm{g} / 1$ in dairy steers, and Olkowski et al. ${ }^{(46)}$ reported this concentration to be $24 \cdot 85$ (SD 10.1) $\mu \mathrm{g} / \mathrm{l}$ in beef cattle.

\section{Subacute ruminal acidosis alters thiamine status in ruminal fluid}

Our previous study ${ }^{(11)}$ demonstrated that high-grain-induced SARA alters the thiamine status in ruminal fluid, the thiamine concentration in SARA cows $(2.97 \mu \mathrm{g} / \mathrm{l})$ was lower than that in control cows $(7 \cdot 88 \mu \mathrm{g} / \mathrm{l})$. This decrease in thiamine concentrations in rumen fluid is mainly caused by an increased thiamine requirement, decreased bacterial thiamine synthesis and increased thiamine degradation in the rumen compared with a high forage diet, and these three possible reasons are explained separately below.

First, when SARA is induced by a high-grain diet, many dietary carbohydrates are fermented and converted into large amounts of pyruvate. Then, pyruvate is converted to lactate by lactate dehydrogenase ${ }^{(47)}$ or degraded to acetyl-CoA and formate by pyruvate formate-lyase ${ }^{(48)}$. TPP is the cofactor of pyruvate formate-lyase ${ }^{(49)}$, therefore, more thiamine is required and used for the decarboxylation of pyruvate, which thus contributes to decreasing the thiamine content in the rumen. Once thiamine deficiency occurs, the conversion of pyruvate to acetyl-CoA is blocked, and the flow of pyruvate to lactate is enhanced, which will aggravate SARA in dairy cows.
Second, the thiamine requirement in ruminants is mainly met by bacterial synthesis in the rumen ${ }^{(5)}$. Magnusdottir et al. ${ }^{(50)}$ noted that thiamine synthesis is most prevalent in Bacteroidetes and Fusobacteria among thiamine-synthesising bacteria. Silverman \& Werkman ${ }^{(51)}$ reported that certain propionateproducing bacteria make thiamine or its intermediates, and Bacteroidetes is the main genus that produces propionate from carbohydrates by the succinate pathway ${ }^{(52)}$. Pan et al. ${ }^{(33)}$ found that the ruminal thiamine content was positively correlated with the genera Bacteroidetes, Fibrobacter and Pyramidobacter and deduced that these genera play important roles in thiamine biosynthesis. However, the abundance of Pyramidobacter ${ }^{(33)}$, Bacteroidetes $^{(53,54)}$ and Fibrobacter ${ }^{(55)}$ in the rumen was reduced by SARA induction. As a result, total bacterial thiamine synthesis in the rumen decreases, which may contribute to the altered thiamine status in ruminal fluid.

In addition, thiamine deficiency can occur due to increased thiamine degradation by thiaminase in the rumen ${ }^{(56)}$. Harmeyer \& Kollenkirchen ${ }^{(57)}$ reported that approximately $90 \%$ of thiamine in the rumen is present in particle-free rumen fluid as free thiamine and is readily accessible to extracellular microbial thiaminase ${ }^{(58)}$. A decrease in ruminal $\mathrm{pH}$ caused by high-grain diets was thought to increase thiaminase production ${ }^{(56)}$. C. sporogenes and a few species of Bacillus are the main culprits of ruminal thiaminase ${ }^{(32)}$; these species have optimum $\mathrm{pH}$ values of 5.2 and 5.6, respectively ${ }^{(31)}$. The growth of $C$. sporogenes and Bacillus increased when SARA (ruminal pH below 5.8) was induced by high-grain feeding, resulting in increased thiaminase production and consequent thiamine degradation ${ }^{(59,60)}$. Enhanced thiaminase activity in acidotic ruminal fluid has been reported previously ${ }^{56,59)}$. The above studies indicate that thiamine degradation in the context of SARA also contributes to the altered ruminal thiamine status and that both the synthesis and degradation of thiamine should be considered when explaining the ruminal thiamine status. 


\section{Subacute ruminal acidosis alters the thiamine status in blood}

Ruminal bacteria first synthesise thiamine, which is then absorbed and transported via the portal vein to the liver by active transport and simple diffusion ${ }^{(61)}$. Pan et al. ${ }^{(62)}$ investigated the effect of high-grain feeding on blood thiamine status and found that the blood thiamine concentration in high-grainfed cows $(11.66 \mu \mathrm{g} / \mathrm{l})$ decreased below $13.27 \mu \mathrm{g} / \mathrm{l}$, indicating that high-grain feeding results in thiamine deficiency and alters the blood thiamine status in dairy cows. The blood thiamine content was positively correlated to rumen thiamine concentration $^{(62)}$, so insufficient bacterial thiamine synthesis in the context of SARA partially accounts for the low blood thiamine level ${ }^{(40)}$. On the other hand, ruminants can absorb free thiamine from the rumen by an active transport mechanism ${ }^{(37)}$ involving transporter-1 and -2 (THTR1 and THTR2) ${ }^{(63)}$. THTR1 and THTR2 are $\mathrm{pH}$ sensitive ${ }^{(64)}$, and their expression can be decreased by lipopolysaccharide (LPS) and pro-inflammatory cytokines $^{(63)}$. During SARA challenge, the ruminal $\mathrm{pH}$ declines and LPS production increases in response to high-grain overfeeding, which down-regulates THTR2 expression and consequently represses thiamine transport, thereby contributing to low thiamine concentrations in the blood ${ }^{(62)}$.

Taken together, SARA induction affects ruminal thiamine status by increasing the thiamine requirement, decreasing bacterial thiamine synthesis, and increasing thiamine degradation in the rumen. The decreasing ruminal thiamine concentrations and reducing thiamine absorption and transport contributed to the altered thiamine status in blood.

\section{Thiamine supplementation helps to attenuate subacute ruminal acidosis}

It is well known that SARA induced by overfeeding a high-grain diet decreases the ruminal $\mathrm{pH}$, alters the rumen microbial population, and increases the concentration of LPS in rumen fluid $^{(54,65)}$. Specifically, SARA challenge leads to a reduction in the abundance of cellulolytic bacteria ${ }^{(55)}$, an increase in the proportion of starch-fermenting and lactic acid-producing bacteria ${ }^{(66)}$, and enhanced lysis of gram-negative bacteria associated with increased ruminal LPS ${ }^{(54)}$. The alterations in ruminal LPS and $\mathrm{pH}$ could act synergistically to disrupt barrier function ${ }^{(67)}$, once the epithelium has been breached, mucosa-associated lymphoid tissue cells respond by triggering local inflammation via the LPS/ toll-like receptor 4 (TLR4) signalling pathway, leading to the excessive production of pro-inflammatory cytokines ${ }^{(68,69)}$. Moreover, an impaired gastrointestinal epithelium facilitates the translocation of LPS from the digestive tract into circulation, causing metabolic alterations and systemic inflammation in host cattle ${ }^{(70)}$, which greatly impacts the production and health of dairy cows.

Currently, there is an increasing focus on SARA prevention. Interestingly, our recent studies have shown that dietary thiamine supplementation ( $180 \mathrm{mg} / \mathrm{kg}$ DM intake) may be a new strategy for SARA prevention. As illustrated in Fig. 2, thiamine supplementation

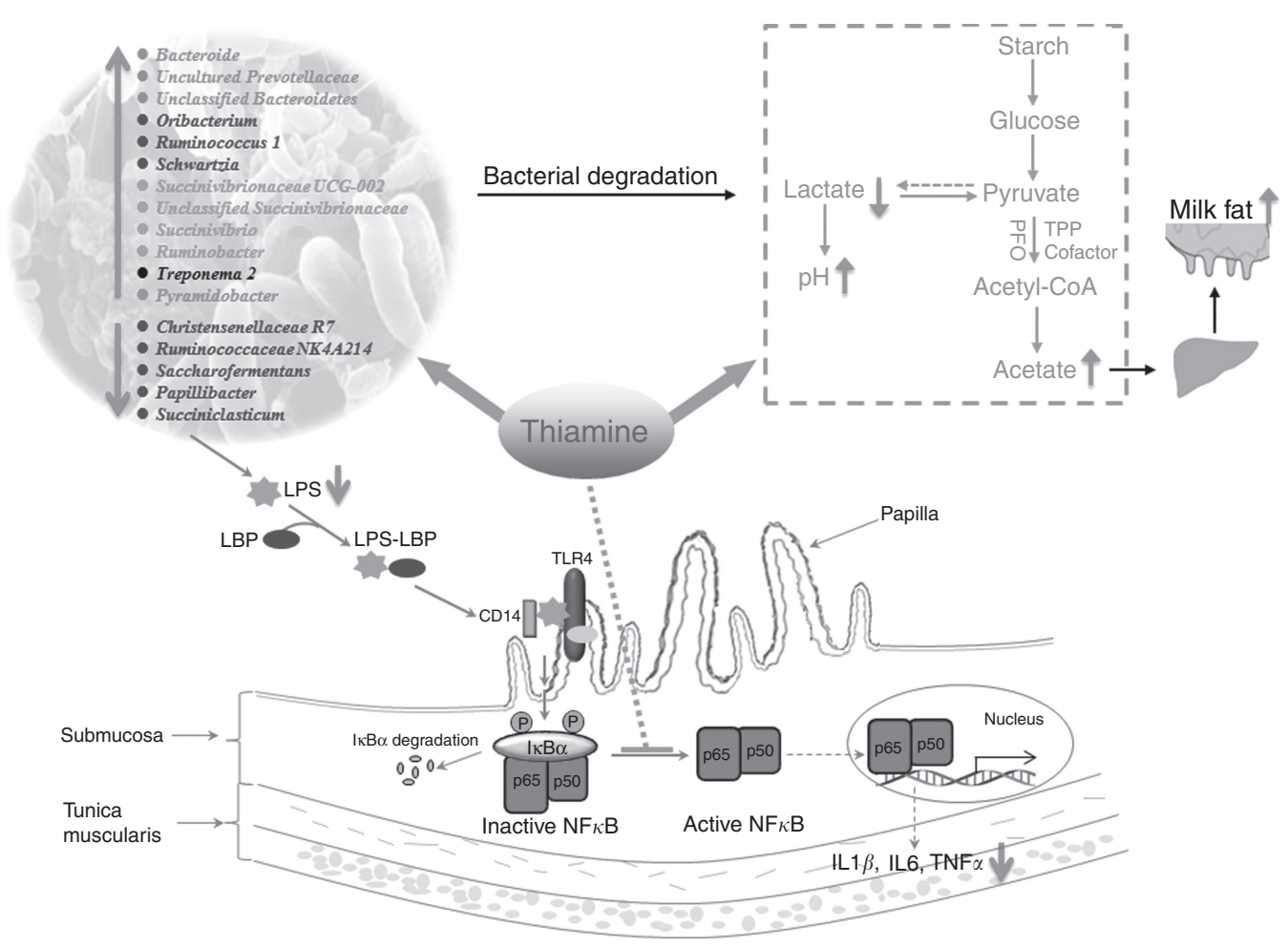

Fig. 2. The potential mechanisms by which thiamine supplementation attenuates high-grain-induced subacute ruminal acidosis in dairy cows. Thiamine supplementation can balance the bacterial community by increasing the abundance of cellulolytic bacteria, including Bacteroides, Ruminococcus 1, Pyramidobacter, Succinivibrio, and Ruminobacter. Such increases enhance fibre degradation and ruminal acetate production; then, increased concentrations of acetate are transported to the mammary gland to increase milk fat synthesis. On the other hand, thiamine supplementation suppresses the ruminal epithelium inflammatory response by decreasing ruminal lipopolysaccharide (LPS) production and repressing NFKB protein activation. TPP, thiamine pyrophosphate; LBP, LPS-binding protein. 
attenuates SARA mainly by improving rumen fermentation ${ }^{(11)}$, balancing the ruminal bacterial community ${ }^{(33,71)}$ and exerting antiinflammatory effects ${ }^{(62)}$ in dairy cows. Specifically, Pan et al. ${ }^{(33)}$ showed that thiamine administration promotes the growth of the bacterial community associated with the degradation of fibre (Ruminococcus 1, Pyramidobacter and Succinivibrio) ${ }^{(72)}$ and polysaccharides (Bacteroides) ${ }^{(73)}$, and decreases the abundance of bacteria positively related to ruminal lactate content (Succiniclasticum and Ruminococcaceae NK4A214). As a result, ruminal fermentation and lactate degradation improved, and ruminal $\mathrm{pH}$ increased $^{(11)}$. Meanwhile, ruminal acetate content in SARA cows supplemented with thiamine increased with a higher abundance of fibre-digesting bacteria, and acetate was then transported to the mammary gland to produce more milk fat ${ }^{(62)}$. On the other hand, during a SARA challenge, the death and lysis of gram-negative rumen bacteria, especially Bacteroidetes spp., are the main sources of free LPS in the rumen ${ }^{(53)}$. Then, free LPS triggers the release of pro-inflammatory cytokines by activating the TLR4/NF $\kappa \mathrm{B}$ signalling pathway ${ }^{(74)}$. In the study by Pan et al. ${ }^{(62)}$, the proportion of Bacteroides increased, with a subsequent decrease in free LPS, upon infusion of thiamine in SARA cows. The decreased LPS content and inhibited $\mathrm{NF} \kappa \mathrm{B}$ activation by exogenous thiamine act together to reduce the production of pro-inflammatory cytokines, and thereby attenuate local inflammation in the rumen epithelium. The anti-inflammatory effects of thiamine have also been demonstrated in rats ${ }^{(75)}$ and humans ${ }^{(76)}$.

\section{Conclusions and future research}

Notwithstanding the knowledge gaps described above, the vital function of thiamine in dairy cows is obvious, including its participation in carbohydrate metabolism in the rumen and host ruminants, regulation of rumen fermentation conditions, and stimulation of milk performance. However, several issues must be addressed to thoroughly understand the thiamine nutritional status in dairy cows. The following are some of the limitations of the current knowledge that need to be resolved:

(1) There is no conclusive dietary recommendation of thiamine in dairy cows. To establish a recommendation, the minimum requirement of thiamine must be estimated. During this process, the amount of thiamine from dietary sources that escapes degradation in the rumen and the amount of thiamine synthesised in the rumen must be ascertained. Unfortunately, knowledge of the factors controlling the amount of thiamine escaping the rumen and thus available for absorption by dairy cows is limited. Therefore, the major challenge in determining the thiamine requirement in dairy cows is predicting thiamine supply dynamically according to different dietary chemical compositions. Hence, more studies are needed to reveal how diet composition (e.g. type of forage, starch concentration and protein concentration) affects the fate of thiamine in the rumen and the amount available for cows at different physiological stages. In addition, the simultaneous determination of ruminal, duodenal, blood and milk biomarkers of thiamine would be useful to understand the fate of thiamine in dairy cows.
(2) Although Pan et $a l^{(33)}$ deduced the possible genera associated with thiamine synthesis based on the positive correlation between thiamine content and the abundance of a particular genera, whether these genera actually participate in thiamine synthesis is still inconclusive. Hence, more experiments, such as the isolation and culture of related bacteria in vitro, are necessary to verify their thiamine synthesis ability. In addition, the rumen is inhabited by a multitude of microorganisms, including bacteria, protozoa, and yeast. Ruminal bacteria on the rumen epithelium, in the liquid or solid fraction, are different because of their distinct ecological niche and metabolic function. Thiamine supplementation has a positive impact on the liquid-associated bacterial community, but whether solid-attached bacteria are affected by thiamine supplementation and whether the anti-inflammatory effect of thiamine is related to its regulation of rumen wall-adherent bacteria are unknown. Moreover, protozoa represent $50 \%$ of the total microbial mass in the rumen and may play crucial roles in thiamine metabolism; therefore, more research on the relationship between ruminal protozoa and thiamine is necessary to understand thiamine metabolism in the rumen.

(3) Most studies on the response of dairy cows to thiamine supplementation have been confined to rumen fermentation and milk performance. In non-ruminant research, the activity of non-thiamine-dependent enzymes, such as succinate dehydrogenase, succinate thiokinase and malate dehydrogenase in the TCA cycle, has been shown to be altered by thiamine deficiency. Therefore, it is necessary to explore the systematic changes in carbohydrate metabolites under conditions of different thiamine status in dairy cows using metabolomics, which will improve the understanding of thiamine function in dairy cows and identify a more sensitive biomarker for thiamine status. In addition to its role in carbohydrate and energy metabolism, the effects of thiamine on cell regulation, immune function, and oxidative damage should be evaluated. The discovery of unknown functions and cattle responses to thiamine will help to improve cow health and productivity and enhance the nutritional value of milk and other dairy products.

\section{Acknowledgements}

The study was financially supported by the Project of National Nature Science Foundation of China (grant no. 31572435). We declare that the National Nature Science Foundation of China had no role in the design and writing of this article.

The authors' contributions are as follows: X. P. wrote and revised the manuscript, X. N. and L. Y. contributed to the preparation of figures, L. J. and B. X. provided critical comments. All authors read and approved the final manuscript.

None of the authors had any conflicts of interest to declare.

\section{References}

1. Bubber P, Ke ZJ \& Gibson GE (2004) Tricarboxylic acid cycle enzymes following thiamine deficiency. Neurochem Int $\mathbf{4 5}$, 1021-1028. 
2. Breves G, Brandt M, Hoeller H, et al. (1981) Flow of thiamin to the duodenum in dairy cows fed different rations. J Agr Sci 96 , 587-591.

3. National Research Council (2001) Vitamins. In Nutrient Requirements of Dairy Cattle, pp. 162-177 [N Grossblatt, editor]. Washington, DC: National Academies Press.

4. Zintzen H (1973) Vitamin $B_{1}$ (Thiamin) in der Ernährung des Wiederkäuers (Vitamin $\mathrm{B}_{1}$ (thiamin) in ruminant nutrition). Übersichten zur Tierernäbrung 1, 273-323.

5. Miller B, Meiske J \& Goodrich R (1986) Effects of grain source and concentrate level on B-vitamin production and absorption in steers. J Anim Sci 62, 473-483.

6. Zinn R, Owens F, Stuart R, et al. (1987) B-vitamin supplementation of diets for feedlot calves. J Anim Sci 65, 267-277.

7. Schwab E, Schwab C, Shaver R, et al. (2006) Dietary forage and nonfiber carbohydrate contents influence B-vitamin intake, duodenal flow, and apparent ruminal synthesis in lactating dairy cows. J Dairy Sci 89, 174-187.

8. Gould DH, McAllister MM, Savage JC, et al. (1991) High sulfide concentrations in rumen fluid associated with nutritionally induced polioencephalomalacia in calves. Am J Vet Res 52, 1164-1167.

9. Shaver RD \& Bal MA (2000) Effect of dietary thiamin supplementation on milk production by dairy cows. J Dairy Sci $\mathbf{8 3}$, 2335-2340.

10. Kholif AM, Hanafy MA, El-Shewy AA, et al. (2009) Effect of supplementing rations with thiamin and/or sodium bicarbonate on milk yield and composition of lactating cows. Egypt J Nutr Feeds 12, 187-195.

11. Pan XH, Yang L, Xue FG, et al. (2016) Relationship between thiamine and subacute rumen acidosis induced by a high grain diet in dairy cows. J Dairy Sci 99, 8790-8801.

12. Subramanya SB, Subramanian VS \& Said HM (2010) Chronic alcohol consumption and intestinal thiamin absorption: effects on physiological and molecular parameters of the uptake process. Am J Physiol Gastrointest Liver Physiol 299, 23-31.

13. McDowell LR (1989) Vitamins in Animal Nutrition. San Diego, CA: Academic Press.

14. Bryant M \& Robinson IM (1961) Some nutritional requirements of the genus Ruminococcus. Appl Microbiol 9, 91-95.

15. Ungerfeld EM, Rust SR \& Burnett R (2009) The effects of thiamine inhibition on ruminal fermentation: a preliminary study. Folia Microbiol (Praha) 54, 521-526.

16. Zhang G, Dai J, Lu Z, et al. (2003) The phosphonopyruvate decarboxylase from Bacteroides fragilis. I Biol Chem 278, 41302-41308.

17. Russell JB (2002) Rumen Microbiology and Its Role in Ruminant Nutrition. Ithaca, NY: Cornell University Press.

18. Solouma GM, Kholif AM, Hamdon HA, et al. (2014) Blood components and milk production as affected by supplementing ration with thiamin in Ewe Sohagi sheep. Life Sci J 11, 60-66.

19. Rowghani E, Zamiri MJ \& Ebrahimi SR (2006) Effects of monensin and thiamin and their combinations on feedlot performance, blood glucose, BUN levels and carcass characteristics of Mehraban lambs fed a high concentrate diet. Pak J Bio Sci 9, 2835-2840.

20. Silzell SA, Hellwig DH, Kegley EB, et al. (2002) Effects of supplemental thiamin on growth performance and immune function in stressed stocker cattle. J Appl Anim Res 22, $145-156$.

21. National Research Council (2012) Nutrient Requirements of Swine, 11th rev. ed. Washington, DC: National Academies Press.

22. Castagnino DS, Seck M, Beaudet V, et al. (2016) Effects of forage family on apparent ruminal synthesis of B vitamins in lactating dairy cows. J Dairy Sci 99, 1884-1894.
23. Beaudet V, Gervais R, Graulet B, et al. (2016) Effects of dietary nitrogen levels and carbohydrate sources on apparent ruminal synthesis of some B vitamins in dairy cows. J Dairy Sci $\mathbf{9 9}$, 2730-2739.

24. McDowell LR (2000) Vitamins in Animal and Human Nutrition. Iowa, NY: Iowa State University Press.

25. Tafaj M, Schollenberger M, Feofilowa J, et al. (2006) Relationship between thiamine concentration and fermentation patterns in the rumen fluid of dairy cows fed with graded concentrate levels. J Anim Physiol Anim Nutr (Berl) 90, 335-343.

26. Kon SK \& Porter JWG (1954) The intestinal synthesis of vitamins in the ruminant. Vitamins and Hormones. Adv Res Appl 12, 53-68.

27. Castagnino DS, Kammes KL, Allen MS, et al. (2016) Particle length of silages affects apparent ruminal synthesis of B vitamins in lactating dairy cows. J Dairy Sci 99, 6229-6236.

28. Seck M, Linton JV, Allen MS, et al. (2017) Apparent ruminal synthesis of B vitamins in lactating dairy cows fed diets with different forage-to-concentrate ratios. J Dairy Sci 100, 19141922.

29. Santschi DE, Berthiaume R, Matte JJ, et al. (2005) Fate of supplementary B-vitamins in the gastrointestinal tract of dairy cows. J Dairy Sci $\mathbf{8 8}, 2043-2054$.

30. Buziassy C \& Tribe DE (1960) The synthesis of vitamins in the rumen of sheep. I. The effect of diet on the synthesis of thiamine, riboflavin, and nicotinic acid. Crop Pasture Sci 11, 989-1001.

31. Boyd JW \& Walton JR (1977) Cerebrocortical necrosis in ruminants attempt to identify source of thiaminase in affected animals. J Comp Pathol 87, 581-589.

32. Brent BE \& Bartley EE (1984) Thiamin and niacin in the rumen. J Anim Sci 59, 813-822.

33. Pan X, Xue F, Nan X, et al. (2017) Illumina sequencing approach to characterize thiamine metabolism related bacteria and the impacts of thiamine supplementation on ruminal microbiota in dairy cows fed high-grain diets. Front Microbiol 8, 1818.

34. Hoeller H, Fecke M \& Schaller K (1977) Permeability to thiamin of the sheep rumen wall. J Anim Sci 44, 158-161.

35. Smith RM \& Marston HR (1970) Production, absorption, distribution and excretion of vitamin $\mathrm{B}_{12}$ in sheep. Br J Nutr $\mathbf{2 4}$, 857-877.

36. Rérat A, Champigny O \& Jacquot R (1959) Modalités de l'absorption vitaminique chez les ruminants: forme et disponibilité des vitamines $\mathrm{B}$ du bol alimentaire aux différents niveaux digestifs (Modalities of vitamin absorption in ruminants: form and availability of $\mathrm{B}$ vitamins from the alimentary bolus at different digestive levels). C R Acad Sci (Paris) 249, 12741276.

37. McDowell LR (2012) Vitamins in Animal Nutrition: Comparative Aspects to Human Nutrition. London: Academic Press.

38. Breves G, Hoeller H, Harmeyer J, et al. (1980) Thiamin balance in the gastrointestinal tract of sheep. J Anim Sci 51, $1177-1181$

39. Mao S, Huo W, Liu J, et al. (2016) In vitro effects of sodium bicarbonate buffer on rumen fermentation, levels of lipopolysaccharide and biogenic amine, and composition of rumen microbiota. J Sci Food Agric 97, 1276-1285.

40. Dabak M \& Gul Y (2004) Thiamine deficiency in sheep with chronic rumen acidosis. Vet $\operatorname{Rec} \mathbf{1 5 4}, 58-59$.

41. Karapinar T, Dabak M \& Kizil O (2010) Thiamine status of feedlot cattle fed a high-concentrate diet. Can Vet J $\mathbf{5 1}$, 1251-1253.

42. Rehm WF, Zerobin K, Christeller S, et al. (1971) Experiments with a new diagnostic method on vitamin B, deficiency in cattle. Berl Muin Tierairztl Wochenschr 84, 64-67.

43. Pill AH (1967) Evidence of thiamine deficiency in calves affected with cerebrocortical necrosis. Vet Rec 81, 178-181. 
44. Hill JH, Rammell CG \& Forbes S (1988) Blood thiamine levels in normal cattle and sheep at pasture. New Zeal Vet J 36, 49-50.

45. Gooneratne SR, Olkowski AA, Klemmer RG, et al. (1989) High sulfur related thiamine deficiency in cattle: a field study. Can Vet J 30, 139-147.

46. Olkowski AA, Christensen DA \& Rousseaux CG (1991) Association of sulfate-water and blood thiamine concentration in beef cattle: field studies. Can J Anim Sci 71, 825-832.

47. Chen L, Luo Y, Wang H, et al. (2016) Effects of glucose and starch on lactate production by newly isolated Streptococcus bovis S1 from Saanen Goats. Appl Environ Microbiol 82, 5982-5989.

48. Asanuma N \& Hino T (2000) Effects of pH and energy supply on activity and amount of pyruvate formate-lyase in Streptococcus bovis. Appl Environ Microbiol 66, 3773-3777.

49. Knappe J, Schacht J, Mockel W, et al. (1969) Pyruvate formatelyase reaction in Escherichia coli. The enzymatic system converting an inactive form of the lyase into the catalytically active enzyme. Eur J Biochem 11, 316-327.

50. Magnusdottir S, Ravcheev D, de Crecy-Lagard V, et al. (2015) Systematic genome assessment of B-vitamin biosynthesis suggests co-operation among gut microbes. Front Genet 6, 148.

51. Silverman M \& Werkman $\mathrm{CH}$ (1939) Adaptation of the propionic-acid bacteria to vitamin $\mathrm{B}_{1}$ synthesis including a method of assay. $J$ Bacteriol 38, 25-32.

52. Louis P, Hold GL \& Flint HJ (2014) The gut microbiota, bacterial metabolites and colorectal cancer. Nat Rev Microbiol 12 661-672.

53. Mao SY, Zhang RY, Wang DS, et al. (2013) Impact of subacute ruminal acidosis (SARA) adaptation on rumen microbiota in dairy cattle using pyrosequencing. Anaerobe 24, 12-19.

54. Khafipour E, Krause DO \& Plaizier JC (2009) A grain-based subacute ruminal acidosis challenge causes translocation of lipopolysaccharide and triggers inflammation. J Dairy Sci $\mathbf{9 2}$, 1060-1070.

55. Fernando SC, Purvis HT, Najar FZ, et al. (2010) Rumen microbial population dynamics during adaptation to a highgrain diet. Appl Environ Microbiol 76, 7482-7490.

56. Brent BE (1976) Relationship of acidosis to other feedlot ailments. J Anim Sci 43, 930-935.

57. Harmeyer J \& Kollenkirchen U (1989) Thiamin and niacin in ruminant nutrition. Nutr Res Rev 2, 201-225.

58. Edwin E \& Jackman R (1970) Thiaminase I in the development of cerebrocortical necrosis in sheep and cattle. Nature $\mathbf{2 2 8}$, $772-774$.

59. Randhawa S, Ahuja A \& Rathor S (1988) Effect of lacticacidosis on histamine and thiamine levels in buffalo calves. Indian J Anim Sci 58, 1019-1023.

60. Dunlop R (1998) Polioencephalomalacia (Cerebrocortical necrosis). In Merck Veterinary Manual, pp. 960-963 [SE Aiello, editor]. Philadelphia, PA: Merck \& Co Inc.

61. Bräunlich K \& Zintzen H (1976) Vitamin $B_{1}$ in Animal Nutrition. Basel: Hoffmann-La Roche.

62. Pan XH, Yang L, Beckers Y, et al. (2017) Thiamine supplementation facilitates thiamine transporter expression in the rumen epithelium and attenuates high-grain-induced inflammation in low-yielding dairy cows. J Dairy Sci 100, 5329-5342.

63. Zhu E, Fang L, Subramanian V, et al. (2015) Lipopolysaccharide and cytokines inhibit thiamine uptake and thiamine transporter gene expression In C2c12 myoblasts. Am J Respir Crit Care Med 191, A4361.

64. Arun R, Antoinette E, I, David G, et al. (2001) SLC19A3 encodes a second thiamine transporter ThTr2. Biochimica et Biophysica Acta 1537, 175-178.

65. Plaizier JC, Li S, Le Sciellour M, et al. (2014) Effects of duration of moderate increases in grain feeding on endotoxins in the digestive tract and acute phase proteins in peripheral blood of yearling calves. J Dairy Sci 97, 7076-7084.

66. Khafipour E, Li S, Plaizier JC, et al. (2009) Rumen microbiome composition determined using two nutritional models of subacute ruminal acidosis. Appl Environ Micro 75, 7115-7124.

67. Emmanuel DG, Madsen KL, Churchill TA, et al. (2007) Acidosis and lipopolysaccharide from Escherichia coli B:055 cause hyperpermeability of rumen and colon tissues. J Dairy Sci $90,5552-5557$.

68. Kurashima Y, Goto Y \& Kiyono H (2013) Mucosal innate immune cells regulate both gut homeostasis and intestinal inflammation. Eur J Immunol 43, 3108-3115.

69. Zhang R, Zhu W \& Mao S (2016) High-concentrate feeding upregulates the expression of inflammation-related genes in the ruminal epithelium of dairy cattle. J Anim Sci Biotechnol 7, $42-55$.

70. Gressley TF (2014) Inflammatory responses to sub-acute ruminal acidosis. In 25th Annual Florida Ruminant Nutrition Symposium, Gainesville, 4 February, pp. 28-41.

71. Wang H, Pan X, Wang C, et al. (2015) Effects of different dietary concentrate to forage ratio and thiamine supplementation on the rumen fermentation and ruminal bacterial community in dairy cows. Anim Prod Sci 55, 189-193.

72. Bainbridge ML, Cersosimo LM, Wright AD, et al. (2016) Rumen bacterial communities shift across a lactation in Holstein, Jersey and Holstein x Jersey dairy cows and correlate to rumen function, bacterial fatty acid composition and production parameters. FEMS Microbiol Ecol 92, fiw059.

73. Flint HJ, Bayer EA, Rincon MT, et al. (2008) Polysaccharide utilization by gut bacteria: potential for new insights from genomic analysis. Nat Rev Microbiol 6, 121-131.

74. Lin ST, Wang Y, Xue Y, et al. (2008) Tetrandrine suppresses LPS-induced astrocyte activation via modulating IKKsIkappaBalpha-NF-kappaB signaling pathway. Mol Cell Biochem 315, 41-49.

75. Shoeb M \& Ramana KV (2012) Anti-inflammatory effects of benfotiamine are mediated through the regulation of the arachidonic acid pathway in macrophages. Free Radical Bio Med 52, 182-190.

76. Gonzalez-Ortiz M, Martinez-Abundis E, Robles-Cervantes JA, et al. (2011) Effect of thiamine administration on metabolic profile, cytokines and inflammatory markers in drug-naive patients with type 2 diabetes. Eur J Nutr 50, 145-149. 